meaning accurately. This principle applies equally to data gathered from patients. The difficulties of interpreting information from patients should not detract from the aim of involving patients as fully as possible in their health care. Rather, this should act as an even greater incentive to research into communications between patients and health professionals.

TOM SENSKY

Charing Cross and Westminster Medical School,

West Middlesex University Hospital,

Isleworth,

Middlesex TW7 6AF

JOSÉ CATALAN Senior Lecturer in Liaison Psychiatry

Charing Cross and Westminster Medical School,

Academic and Clinical Department of

Psychological Medicine,

London SW 1P 2NS

1 Frater A, Costain D. Any better? Outcome measures in medical audit. BMf 1992;304:519-20

2 Ende J, Kazis L, Ash A, Moskowitz MA. Measuring patients' desire for autonomy: decision making and information-seeking preference among medical patients. $f$ Gen Intern Med 1989;4:23-30

3 Brener N, Andrews H, Catalan J, et al. Whose health is it? The views of HIV patients and their carers about decision-making and information seeking. In: Abstracts of the seventh international conference on AIDS. Florence: 1991

4 Sensky T. Patients' reactions to illness: cognitive factors determine responses and are amenable to treatment. $B M \mathcal{F}^{1}$ 1990;300:622-3.
5 Kirmayer LJ. Cultural variations in the response of psychiatric disorders and emotional distress. Soc Sci Med 1989;29:327-39.

6 Levine J, Warrenburg S, Kerns R, et al. The role of denial in recovery from coronary heart disease. Psychosom Med 1987;49:109-17.

7 Fricchione GL, Howanitz E, Jandorf L, Kroessler D, Zervas I, Woznicki RM. Psychological adjustment to end-stage renal disease and the implications of denial. Psychosomatics 1992;33: $85-91$.

8 Flor $\mathrm{H}$, Turk DC. Chronic pain and rheumatoid arthritis: predicting pain and disability from cognitive variables. $\mathcal{F}$ Behav Med 1988;11:251-65.

9 Taylor SE, Lichtman RR, Wood JV. Attributions, beliefs about control, and adjustment to breast

cancer. I Person Soc Psychology 1984;46:489-502.
10 Devins GM, Binik YM, Gorman P, et al. Perceived self-efficacy, outcome expectancies, an o negative

11 Mayou R, Hawton K. Prevalence of psychiatric morbidity in the general hospital. Br F Psychiatr Mayou R, Hawton

12 Beck AT. Cognitive therapy and the emotional disorders. London: Penguin, 1990.

13 Sensky T, Wright J. Cognitive therapy with medical patients. In: Wright J, Thase M, Ludgate Jo Beck AT, eds. Cognitive therapy with inpatients: developing a cognitive milieu. New York: Guilford 1992:219-46.

14 Affleck G, Tennen H, Pfeiffer C, Field J. Appraisals of control and predictability in adapting to chronic disease. I Pers Soc Psychol 1987;53:273-9.

15 Rosenberg SJ, Peterson RA, Hayes JR. Coping behaviours among depressed and nondepressect) medical inpatients. $f$ Psychosom Res 1987;31:653-8.

16 Parker J, McRae C, Smarr K, et al. Coping strategies in rheumatoid arthritis. 7 Rheumato 5 1988;15:1376-83.

17 Rosenberg SJ, Peterson RA, Hayes JR, Hatcher J, Headen S. Depression in medical in-patients

Brf Med Psychol 1988;61:245-54.
18 Campbell A, Converse PE, Rodgers WL. The quality of American life. New York: Russell Sag@ Foundation, 1975.

19 Sensky T. Measurement of quality of life in end-stage renal failure. N Engl f Med 1988;319:3153.

20 Stewart AL, Hays RD, Ware JE Jr. The MOS short-form general health survey. Med Cares 1988;26:724-32.

21 Brazier JE, Harper R, Jones NMB, et al. Validating the SF-36 health survey questionnaire: a new

outcome measure for primary care. BMf 1992;305:160-4.
22 Wachtel T, Piette J, Mor V, Stein M, Fleishman J, Carpenter C. Quality of life in persons witto human immunodeficiency virus infection: measurement by the medical outcomes studN instrument. Ann Intern Med 1992;116:129-37.

23 Wells KB, Stewart AL, Hays RD, et al. The functioning and well-being of depressed patients: results from the medical outcomes study. IAMA 1989;262:914-9.

\title{
Department of Health reports on tobacco advertising
}

\section{A ban would significantly cut consumption}

The European Community directive to ban tobacco advertising was proposed over a year ago. Strongly supported by the British health and medical establishment, the ban has been consistently opposed by the British government. The long awaited report on the effects of tobacco advertising by the Department of Health's chief economic adviser is now issued as a discussion document. ${ }^{2}$ It includes a wide ranging assessment of worldwide evidence and presents its own new empirical analysis. Its aim is to assess whether tobacco advertising affects aggregate demand for tobacco products and not simply the share of the market taken by individual products, as is argued by the tobacco industry.

The report's main and strongest evidence comes from studies of tobacco consumption analysed by price, income, advertising, and publicity about toabacco's harmful effects. Advertising is notoriously difficult to model because it takes time to reach its full effect, which may then last for many years. Three main types of analyses were studied: analyses of year by year fluctuations in cigarette consumption, cross sectional comparisons between countries, and analyses of cigarette consumption in countries before and after they banned tobacco advertising.

The report concludes, with reason, that the studies of bans are the most satisfactory. These present a direct measure of the total impact of tobacco advertising, controlling for price and other factors, and avoid the problem of direction of causation present in cross sectional studies. There have been bans in New Zealand (1990), estimated to have reduced consumption by $5 \cdot 5 \%{ }^{3}$; Canada (1989), a rather confused situation but estimated to have reduced consumption by $4 \%$; and Finland (1977), estimated at 7\%. the ban in Norway (1975) had not been formally evaluated the Department of Health's economists analysed its effects them- selves. They estimated that the average consumption of tobacco per adult fell by $16 \%$ due to the ban; a double hurdle model, simultaneously estimating the effect on prevalenc® and amount smoked, suggested a long term reduction of $9 \% \overrightarrow{\overrightarrow{0}}$ All these studies suggest sizeable and significant effects o tobacco advertising bans.

A cross sectional study of 22 countries belonging to the Organisation for Economic Cooperation and Developmen reported a significant effect of different levels of advertising restrictions. ${ }^{5}$ Countries were scored from 0 to 10 according to severity (Britain scored 6 in 1986), and the study suggeste $\bar{\phi}$ that each point was associated with a $1.5 \%$ decrease in consumption. This would imply that an advertising baro would cut consumption in Britain by $6 \%$. The repor points out the difficulty of interpreting the direction of causation-negative social attitudes to smoking may be related to both low tobacco consumption and stricter adver tising controls.

The third and most numerous group comprise time series ${ }_{\sigma}^{\omega}$ The report notes that 13 reported only positive effects of tobacco advertising on consumption, one reported a negative effect, and five reported both (in different equations). The authors note that "the preponderance of positive resultso points to the conclusion that advertising does have a positive्ष effect on consumption." British researchers work within the limitation that published data on tobacco advertising omie spending on billboard advertising (estimated as 30-40\% of total advertising spend ${ }^{6}$ ) or sponsorship. The leading studie@ in this category were published some years ago, and the first implied that a ban would reduce consumption by abou傮 $7 \cdot 5 \%,{ }^{7}$ which would take some time to show its full effect.

The report emphasised that analyses of time series are likely seriously to underestimate the real effects of a ban: annual 
fluctuations will relate to the least productive slice of advertising expenditure on the reasonable assumption that advertising is subject to diminishing returns. Accordingly, an outright ban is likely to have far more effect than marginal changes. The report also considered survey evidence that nearly half of all smokers agree that "smoking cannot be really dangerous or the government would ban cigarette advertising."

The conclusion from the evidence amassed in the Department of Health's report is clearly that tobacco advertising affects the level of tobacco consumption. The government's white paper The Health of the Nation has set a target to reduce consumption of cigarettes by $40 \%$ and the prevalence of smoking to $20 \%$ by $2000 .{ }^{9}$ To this end the government has committed itself to maintaining the real value of cigarette excise duty. This is by no means sufficient to achieve these targets, ${ }^{10}$ which are necessarily ambitious, to cut morbidity and mortality from cancer, heart disease, and stroke.

Even with a considerable annual increase in real price and health education meeting these targets without an advertising ban is unlikely. The government has already banned tobacco advertising on television and accepts the need to control advertising. If control is good a ban must be better, and anything less would seem second best for health.

MRC Epidemiology and Medical Care Unit,

JOY TOWNSEND

Wolfson Institute of Preventive Medicine,

Medical College of St Bartholomew's Hospital,

London EC1M 6BQ

1 Department of Health Economics and Operational Research Division. Effect of tobacco advertising on tobacco consumption: a discussion document revieving the evidence. London: Department of Health, 1992

Warden J. Smoke screen over advertising bans. BM7 1992;305:1115.

3 New Zealand Department of Health. Health or tobacco: an end to tobacco advertising and promotion. Wellington: Toxic Substances Board, 1989

Pekurinen M. The demand for tobacco products in Finland. Br f Addiction 1989;84:1183-92.

5 Laugesen M, Meads C. Tobacco advertising restrictions, price, income, and tobacco consumption in OECD countries, 1960-1986. Br F Addiction 1991;86:1343-54.

6 Radfar M. The effect of advertising on total consumption of cigarettes in the UK. European Economic Review 1985;29:225-31.

McGuinness T, Cowling K. Advertising and the aggregate demand for cigarettes. European Economic Review 1975;6:311-28.

Marsh A, Matheson J. Smoking attitudes and behaviour. London: HMSO, 1983.

9 Secretary of State for Health. The health of the nation: a strategy for health in England. London: HMSO, 1992. (Cmnd 1986.)

10 Townsend J. Policies to halve smoking deaths. Addiction (in press).

\section{Viral diarrhoeas in childhood}

\section{Electron microscopy has improved our understanding}

Despite recent advances in oral rehydration therapy and improved diagnostic techniques an estimated five million preschool children die annually worldwide from the complications of acute, predominantly viral, diarrhoea. ${ }^{1}$ Mortality has plummeted in developed countries, though the number of admissions has not. ${ }^{2}$ This may be due to doctors frequently overestimating the severity of illness and dehydration ${ }^{2-4}$ and wrongly treating patients before admission. This happens in up to one third of children who see their general practitioners; many children receive unnecessary and potentially dangerous drugs. ${ }^{23}$ Fewer than one third receive an oral rehydration solution, ${ }^{2}$ and published guidelines on dietary management are often ignored. ${ }^{5}$

The first enteric virus, Norwalk agent, was identified in diarrhoeal stools by electron microscopy in 1972. ${ }^{6}$ The identification of rotavirus, ${ }^{7}$ enteric adenovirus, astrovirus, and calicivirus followed, and their pathogenicity was subsequently established. Rotaviruses are now recognised as the commonest cause of endemic acute diarrhoea in childhood, accounting annually for an estimated 140 million cases, one million deaths in young children, ${ }^{89}$ and most hospital admissions for diarrhoea in children under $2 .^{9}$ Attack rates are similar in developed and developing countries ${ }^{810}$; many infections are mild or asymptomatic.

Most infections in infants are due to group A rotaviruses, and at least seven serotypes of human rotavirus have been identified within this group. Groups B and C may also cause diarrhoea in humans. Vomiting may be severe, and fever is common. Watery diarrhoea persists for up to seven days and may be complicated by dehydration, acidosis, and transient carbohydrate intolerance.

With improved infant formulas and feeding practices hypernatraemia now occurs rarely in developed countries. Neonatal infection with the virus occurs but is often mild or asymptomatic, with maternal antibodies conferring protection. Recent evidence suggests that extraintestinal infection occurs in immunodeficient children. ${ }^{11}$ Rapid diagnosis can be made by electron microscopic detection of $70 \mathrm{~nm}$ wheel like particles in the stool. Commercial enzyme linked immunoassays for detecting group A rotavirus antigen in the stool are available. The use of the polymerase chain reaction as a research tool to detect rotavirus in stools may provide invaluable epidemiological information. ${ }^{8}$

Enteric adenoviruses serotypes 40 and 41 account for up to a sixth of cases of viral diarrhoea in children in Britain and the United States, ${ }^{910}$ ranking second to rotavirus. One in two children have neutralising antibodies by the age of $4 .{ }^{12}$ Diarrhoea is often protracted, but vomiting and fever are less prominent than with rotavirus. The $80 \mathrm{~nm}$ virus particles in the stool can be identified by electron microscopy, and typing is possible by various techniques.

Diarrhoea due to astrovirus is more common in young children than adults, in whom infection is rarely symptomatic. Symptoms are similar to those of infections with rotaviruses, but dehydration is uncommon. Serological evidence of past infection is present in nearly two thirds of British children by the age of 4 and in nearly $90 \%$ by the age of $10 .^{13}$

Electron microscopy of the stool shows a star shaped particle of 27-30 nm diameter. The recent development of an enzyme linked immunoassay using monoclonal antibodies has enabled the rapid detection of antigen common to all five serotypes in the stool and the clarification of the virus's role. In Thai children astrovirus accounted for $8.6 \%$ of cases of acute diarrhoea, being more common than enteric adenovirus. ${ }^{14}$ In contrast, detection rates were low in children presenting to hospital in the United States with diarrhoea and similar to rates in controls, ${ }^{15}$ and further controlled studies are needed to evaluate the virus's pathogenic role in developed countries.

Although more often implicated in adults, Norwalk virus also causes acute epidemic gastroenteritis in children. Vomiting is frequent, but diarrhoea and dehydration are mild. Serum antibody is not detected in children under 3 but is found in one fifth of children by 5 years of age and in more than three fifths of adolescents. ${ }^{16}$ Diagnosis of this small, round structured virus (27-35 $\mathrm{nm}$ diameter) can be made by electron microscopy or immunoassay. 